\title{
Photocatalytic 3-Component Umpolung Synthesis of 1,3-Diamines
}

\author{
Thomas Rossolini, Jamie A. Leitch, ${ }^{\ddagger}$ Rachel Grainger, ${ }^{\ddagger}$ and Darren J. Dixon., \\ ‡ Department of Chemistry, University of Oxford, Chemistry Research Laboratory, 12 Mansfield Road, Oxford, OX1 3TA, UK \\ $¥$ Astex Pharmaceuticals Ltd, 436 Cambridge Science Park, Milton Road, Cambridge, CB4 0QA, UK
}

\begin{abstract}
A visible-light mediated photocatalytic umpolung synthesis of 1,3-diamines from in situ generated imines and dehydroalanine derivatives is described. Pivoting on a key nucleophilic addition of photocatalytically generated $\alpha$-amino radicals to electron deficient alkenes, this three-component coupling reaction affords 1,3-diamines efficiently and diastereoselectively. The mild protocol tolerates a wide variety of functionalities including heterocycles, pinacol boronates, and aliphatic chains. Application to biologically relevant $\alpha$-amino- $\gamma$-lactam synthesis and extension to 1,3-aminoalcohols is also demonstrated.
\end{abstract}

Recent advances in visible-light photoredox catalysis have facilitated unique approaches to rapidly access complex organic molecules. ${ }^{1}$ The new reactivity enabled by in situ generation of free radical intermediates under mild reaction conditions has led to a variety of new and synthetically powerful carbon-carbon and carbonheteroatom bond forming reactions. ${ }^{2}$ Significant achievements include novel umpolung transformations that have unleashed new reactivity between non-traditional coupling partners. Notably, the reductive coupling of imines and electrophilic species via a putative $\alpha$-amino radical has received great attention in recent years and comprises imine allylation, ${ }^{3}$ alkylation including pinacol coupling, ${ }^{4}$ and arylation (Scheme 1).,

In a continuation of our research programme on photocatalytic amine synthesis, ${ }^{3 \mathrm{~b}, 7}$ we aimed to further explore imine umpolung chemistry towards new electrophilic coupling partners to generate valuable amine containing products that would otherwise be difficult to access. Structures possessing the 1,3-diamine motif are ubiquitous in natural products, useful synthetic molecules, and play key roles as ligands for catalysis as well as in pharmaceutical research. ${ }^{8}$ Despite their widespread application and relevance in bioactive compounds, limited methods for the direct formation of 1,3diamines have been reported. ${ }^{8,9}$ Consequently, novel synthetic approaches to access such 1,3-diamine constructs from abundant and commercially available starting materials would be of general interest and high synthetic value. Inspired by Jui's elegant work on the generation of heteroaryl amino acids, ${ }^{10}$ we sought to investigate the reactivity of dehydroalanine (DHA) derivatives as electrophilic species to engage in radical conjugate addition reactions with in situ generated $\alpha$-amino radicals. Encouraged by successful studies on radical conjugate addition to alkenes, ${ }^{4 b, 11}$ we considered the role of DHAs as Michael acceptors in a new synthetic methodology for the formation of unsymmetric 1,3-diamine constructs and herein we wish to report our findings.

Preliminary investigations focused on the reaction between fluorine tagged imine 1 and bis- $N$-Boc DHA derivative 2 ( 1 eq) under blue LED light irradiation in DMSO using commercial Hantzsch ester (HE1) as the stoichiometric reductant. Pleasingly, the desired reactivity was achieved, and 1,3-diamine derivative 3 was formed in
$47 \%$ isolated yield employing 1 mol \% $\left[\operatorname{Ir}\left(\mathrm{dF}\left(\mathrm{CF}_{3}\right) \mathrm{ppy}\right)_{2}(\mathrm{dtbbpy})\right] \mathrm{PF}_{6}$ as photoredox catalyst (Table 1$)$. Importantly, the yield of this transformation was increased when 2 eq of DHA were employed (Entry 2) and further improved with in situ imine formation, affording the desired product in $93 \%$ yield (Entry 3). Additional optimization experiments were then conducted in an attempt to increase the diastereomeric ratio ( $\mathrm{dr}$ ). The use of a substituted Hantzsch ester (HE3) was found to be beneficial by improving the dr to 2:1 without affecting reaction yield (Entry 6). Notably, switching to a binary $\mathrm{MeOH} / \mathrm{DMSO}$ solvent system allowed improvement of both reaction efficiency and diastereoselectivity (Entries 9-12). Following further optimization, $\mathrm{MeOH} / \mathrm{DMSO}$ (3:2) led to full conversion whilst imparting good diastereoselectivity; compound 3 was obtained in $99 \%$ isolated yield as a 4:1 (anti:syn) separable mixture of diastereoisomers (Entry 12). The relative stereochemical configuration of the major diastereoisomeric product of $\mathbf{3}$ was confirmed as anti by single crystal X-ray diffraction (Scheme 2B). ${ }^{12}$

Scheme 1. Photocatalytic Platform for Umpolung Chemistry of Imines: Applications to 1,3-Diamine Synthesis

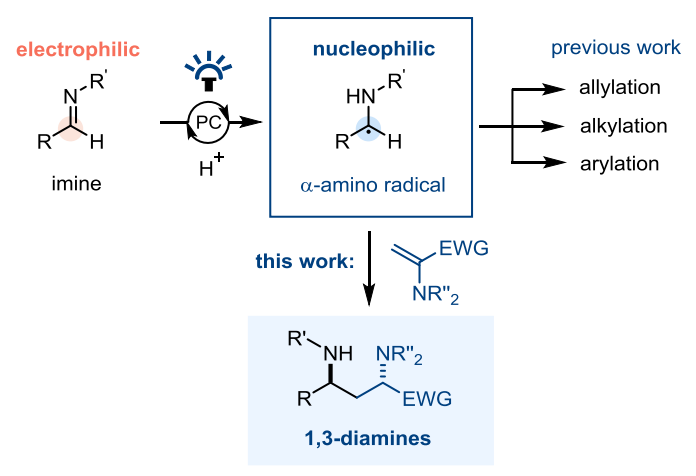


Table 1. Optimization of Photocatalytic Umpolung Diamine Synthesis. ${ }^{13}$

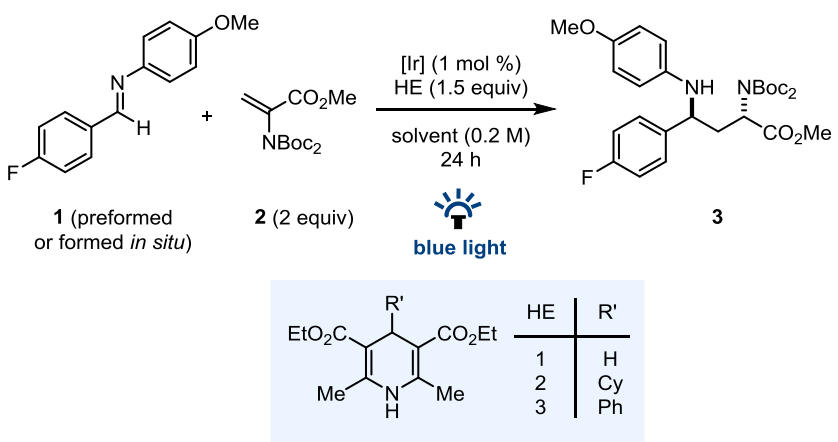

$\begin{array}{cccccc}\text { entry }^{\mathrm{a}} & 1 & \text { HE } & \text { solvent } & 3(\%)^{\mathrm{b}} & \mathrm{dr} \\ 1^{\mathrm{c}} & \begin{array}{c}\text { pre- } \\ \text { formed }\end{array} & \text { HE1 } & \text { DMSO } & 47^{\mathrm{d}} & 1.5: 1 \\ 2 & \begin{array}{c}\text { pre- } \\ \text { formed }\end{array} & \text { HE1 } & \text { DMSO } & 79^{\mathrm{d}} & 1.5: 1 \\ 3 & \text { in situ } & \text { HE1 } & \text { DMSO } & 93^{\mathrm{d}} & 1.4: 1 \\ 4^{\mathrm{e}} & \text { in situ } & \text { HE1 } & \text { DMSO } & 0 & - \\ 5 & \text { in situ } & \text { HE2 } & \text { DMSO } & 15 & 1.5: 1 \\ 6 & \text { in situ } & \text { HE3 } & \text { DMSO } & 96 & 2: 1 \\ 7 & \text { in situ } & \text { HE3 } & \text { MeOH } & 16 & 3: 1 \\ 8 & \text { in situ } & \text { HE3 } & \text { EtOH } & 32 & 3.6: 1 \\ 9 & \text { in situ } & \text { HE3 } & \text { EtOH/DMSO (4:1) } & 76 & 3.2: 1 \\ 10 & \text { in situ } & \text { HE3 } & \text { EtOH/DMSO (3:2) } & 100 & 3.2: 1 \\ 11 & \text { in situ } & \text { HE3 } & \text { MeOH /DMSO (7:3) } & 69 & 4.1: 1 \\ 12 & \text { in situ } & \text { HE3 } & \text { MeOH/DMSO (3:2) } & 100 & 4: 1\end{array}$

$(99)^{d}$

${ }^{\text {a }}$ Reaction conditions: aldehyde $(0.2 \mathrm{mmol})$, aniline $(0.2 \mathrm{mmol}), 2(0.4 \mathrm{mmol}, 2$ equiv), $\left[\operatorname{Ir}\left(\mathrm{dF}\left(\mathrm{CF}_{3}\right) \text { ppy }\right)_{2}(\mathrm{dtbbpy})\right] \mathrm{PF}_{6}(1 \mathrm{~mol} \%), \mathbf{H E}(0.3 \mathrm{mmol}) .{ }^{\mathrm{b}}{ }^{19} \mathrm{~F}\left\{{ }^{1} \mathrm{H}\right\}$ NMR yield. ${ }^{\mathrm{c}} 1$ equiv of $2 .{ }^{\mathrm{d}}$ Isolated yield. ${ }^{\mathrm{e}}$ No photocatalyst.

With the optimized conditions established, the scope of the photocatalytic umpolung coupling with respect to both the aldehyde and amine components was explored (Scheme 2).

Initially, the effect of electronic variation on the in situ generated $\boldsymbol{\alpha}$-amino radical was examined by changing the para substituents of the arylaldehyde (3-10). Excellent reaction outcomes were observed with both electron-withdrawing and electron-releasing functional groups; although a small drop in reactivity was observed with the strongly electron-withdrawing $\mathrm{CF}_{3}$ substituent (10). ${ }^{14}$ These results tentatively support the proposed intermediacy of a nucleophilic $\alpha$-amino radical species, a conclusion that was further supported by results obtained with pyridyl aldehydes (11, 12), where the more electron rich aromatic ring gave excellent yield and good diastereoselectivity. The substrate scope of this transformation was also successfully expanded to include further heterocyclic rings such as furan, thiophene, pyrrole, and imidazole (13-16) with moderate to good yields. Encouraged by these successful results using substrates with challenging functionalities, we looked to expand the scope of this reaction to include aliphatic carboxaldehyde starting materials. Pleasingly, cyclic (17), a-branched (18), and linear aliphatic chains (19) afforded the desired products with good to excellent yields and good diastereoselectivity. Good effi- ciency was achieved with boronic acid pinacol ester (20), opening up the possibility of combining this transformation to downstream transition metal cross-coupling reactions. To demonstrate the potential application of this methodology in medicinal chemistry, we sought to expand the range of substrates to include more elaborate examples of $\mathrm{N}$-containing heterocycles. Pleasingly, pyrrolo[2,3$b]$ pyridine derivative 21 and $N$-Boc-protected azetidine 22 were synthesized from their respective carboxaldehydes in one step with synthetically useful yields.

We next turned our attention to investigate the scope with respect to the aniline moiety, using $p$-fluorobenzaldehyde as a model substrate. Pleasingly, a broad range of aniline derivatives, from electron-rich to electron-poor, were compatible with this chemistry (23-31). Notably, no undesired downstream cascade reaction was observed when alkyne $\mathbf{2 8}$ was formed, and the expected product was obtained with excellent yield and good diastereoselectivity. 3Aminopyridine (32) and 4-aminophenol (33) derivatives were synthesized with moderate reaction efficiency but good diastereomeric ratio. Moreover, heterocyclic rings such as unprotected benzotriazole, indazole, and benzothiazole were found to be competent amine substrates for in situ imine generation followed by radical conjugate addition with highly efficient product formation (3436). Following the broad range of functional groups tolerated in this reaction, we sought to expand its versatility for the synthesis of analogous 1,3-aminoalcohols via the reductive coupling of carboxaldehydes with DHA derivative 2 . $\beta$-Amino alcohols are important target structures owing to their abundance in bioactive natural products and broad therapeutic utility. ${ }^{15}$ Moreover, great interest for this functionality has been developed due to its pivotal role as the source of chirality in asymmetric synthesis. ${ }^{16}$ We envisaged that the omission of the aniline moiety in our transformation would lead to the ketyl radical, which could be intercepted by the dehydroalanine electrophile to generate the desired 1,3-aminoalcohol relationship. Accordingly, we subjected 4-fluorobenzaldehyde to blue light irradiation with DHA derivative 2 in the presence of the optimal iridium photocatalyst and HE3 as the stoichiometric reductant. We were delighted to observe the formation of $\beta$-amino alcohol 37 in excellent yield and moderate diastereoselectivity (Scheme 2c).

To substantiate the synthetic utility of this methodology in drug discovery applications, $\gamma$-lactam 39, a key intermediate towards a number of CB-1 receptor inverse agonists, was identified as a suitable test case. ${ }^{17}$ Photocatalytic construction of desired 1,3diamine product 38 was achieved in 99\% yield and good diastereomeric ratio from commercially available benzaldehyde and 4-trifluoromethoxyaniline (Scheme 3A). Pleasingly, one-step cyclisation/deprotection of major isomer $\mathbf{3 8}$ under acidic conditions afforded functionalized $\gamma$-lactam 39 in good yield. Condensation of aminolactam 39 with a series of functionalized ketones, followed by addition of trimethylaluminum as previously reported, ${ }^{18}$ is known to give access to a variety of drug candidates such as $\mathbf{4 0}$, which has been shown to exhibit antagonistic activity in the low micromolar range. ${ }^{19}$ 
Scheme 2. (A) Scope of the three-component direct photocatalytic umpolung synthesis of unsymmetrical 1,3-diamines. (B) Single crystal X-ray structure of major diastereoisomer 3; other compounds assigned by analogy. (C) Extension to 1,3-aminoalcohols.

A

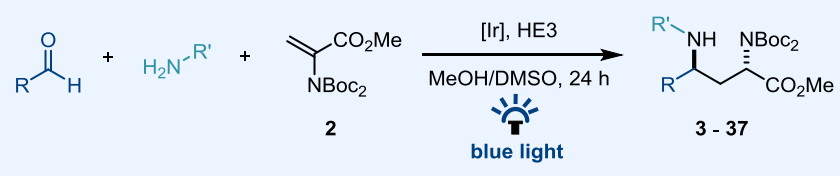

Aldehyde scope
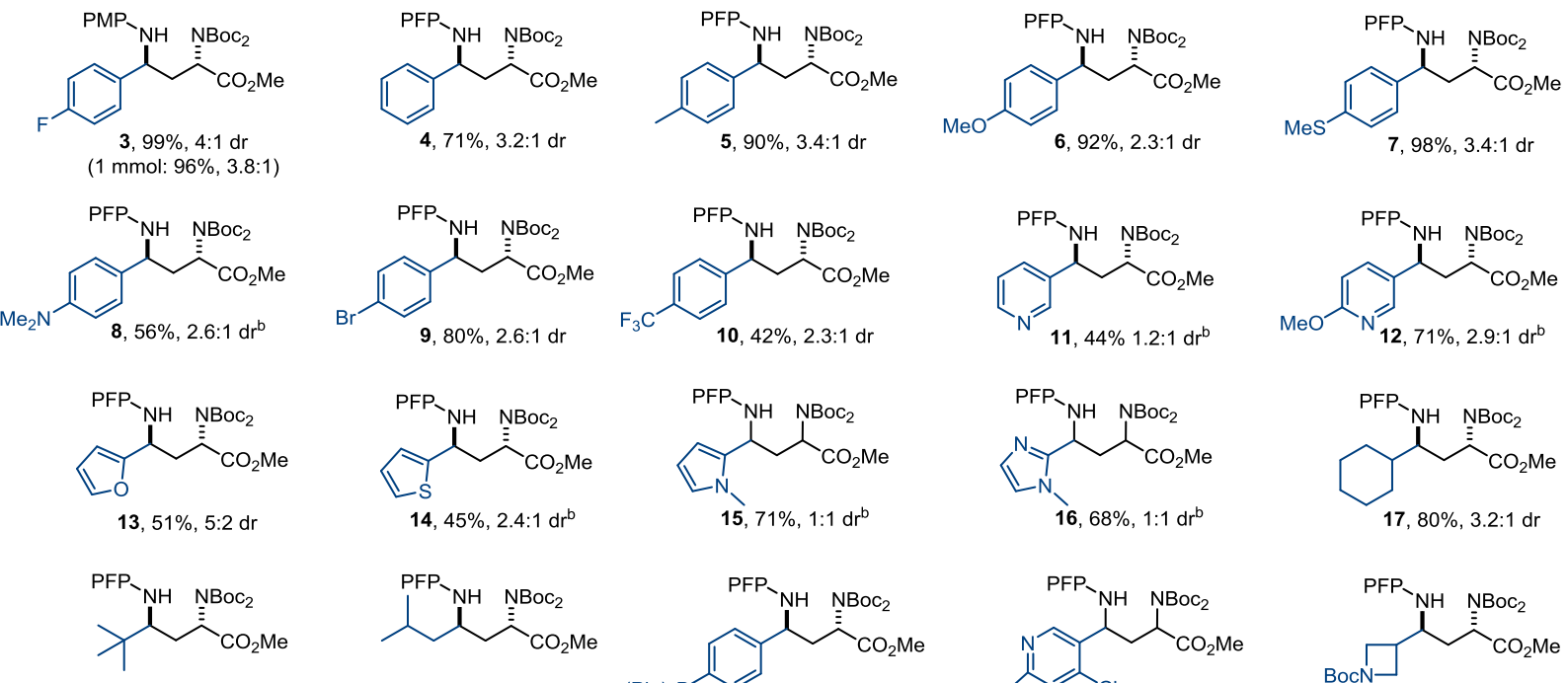

$18,93 \%, 3.8: 1 \mathrm{dr}$

$19,85 \%, 2.4: 1 \mathrm{dr}$
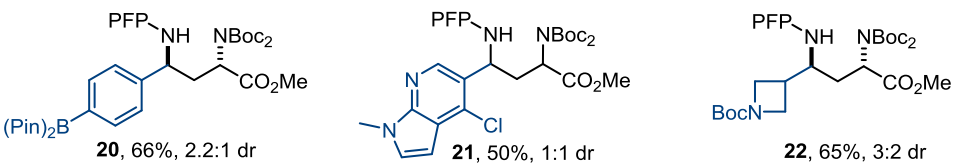

22, $65 \%, 3: 2 \mathrm{dr}$

Aniline scope<smiles>COC(=O)C(CC(Nc1ccccc1)P=P)OC(C)=O</smiles>

23, $94 \%, 2.7: 1 d r$

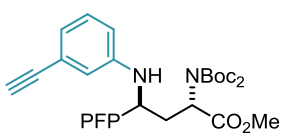

28, $91 \%, 7: 2 d r$

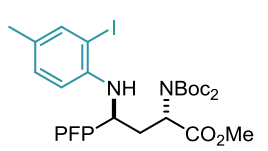

24, $69 \%, 3.3: 1 \mathrm{dr}$

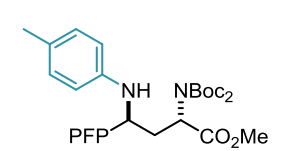

25, $74 \%, 3: 1 d$

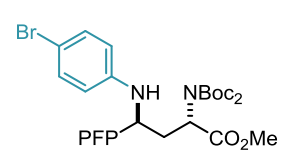

26, $91 \%, 3.4: 1 \mathrm{dr}$

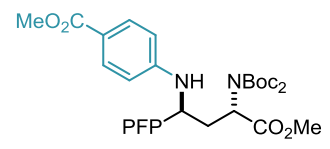

30, $90 \%, 2: 1 \mathrm{dr}$

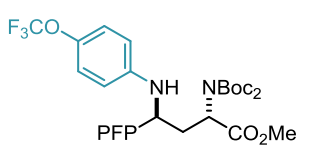

31, 98\%, 3.3:1 dr

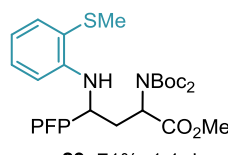

$29,71 \%, 1: 1 \mathrm{dr}$

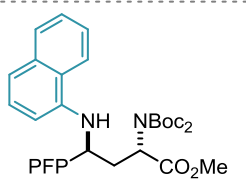

27, $75 \%, 2: 1 d r$

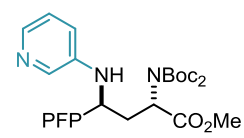

32, $50 \%, 3.3: 1 \mathrm{dr}^{\mathrm{b}}$

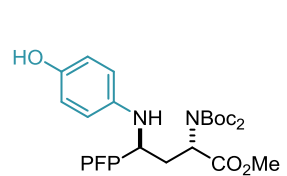

33, $55 \%, 2.8: 1 d$

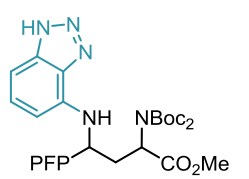

34, $86 \%, 1: 1 d r$

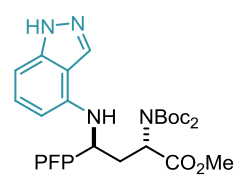

35, $80 \%, 2.8: 1 \mathrm{dr}$

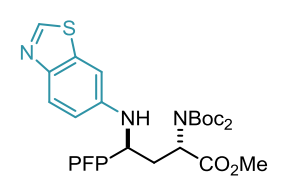

36, $78 \%, 3: 1 \mathrm{dr}$
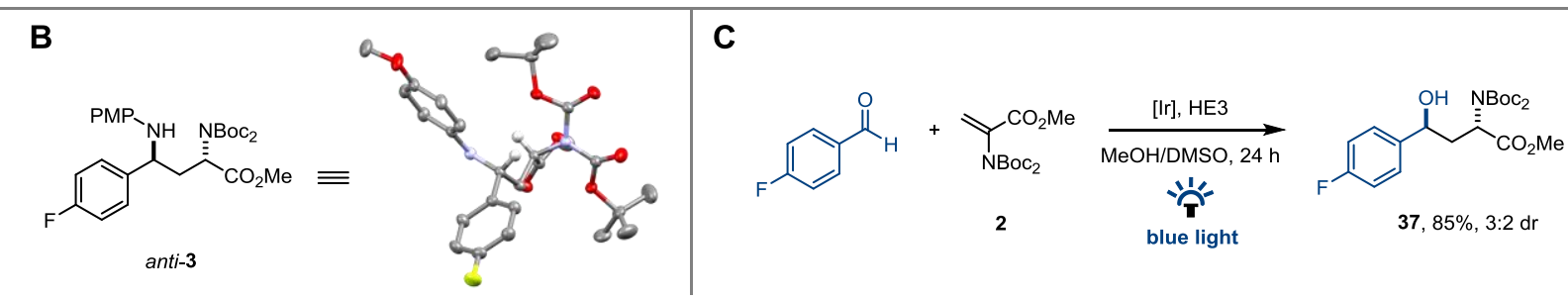

PMP $=p$-methoxyphenyl; PFP $=p$-fluorophenyl; Pin $=$ pinacol. ${ }^{a}$ Combined isolated yields given for minor and major diastereoisomers; see SI for experimental details. ${ }^{b}$ Reaction time $48 \mathrm{~h}$.

From a mechanistic standpoint, aligned with previous investigations, ${ }^{3}$ we suggest that initially the Hantzsch ester is capable of reducing the photoexcited iridium catalyst generating a highly reducing $\mathrm{Ir}^{\mathrm{II}}$ species $\left(E_{1 / 2}^{0}=-1.37 \mathrm{~V}\right.$ vs. SCE in $\left.\mathrm{CH}_{3} \mathrm{CN}\right){ }^{2 \mathrm{~b}}$ Previous reports $^{3,4 a, 7}$ have proposed that partially oxidized Hantzsch esters
$\left(\mathrm{HE}_{+} \cdot\right)_{\text {can }}$ donate a proton in proton coupled electron transfer (PCET) mechanisms. ${ }^{20}$ PCET would allow electrochemically robust aryl-imine derivatives $\left(E_{1 / 2}^{0}=1.90 \mathrm{~V} \text { vs. SCE in } \mathrm{CH}_{3} \mathrm{CN}\right)^{21}$ to be readily reduced by the iridium species. This would generate the key nucleophilic $\alpha$-amino radical which can intercept the DHA 
coupling partner. Subsequent single electron reduction and protonation of the addition intermediate would afford the 1,3diamine product 3 .

Scheme 3. (A) Derivatization and application to drug synthesis. (B) Plausible mechanism.

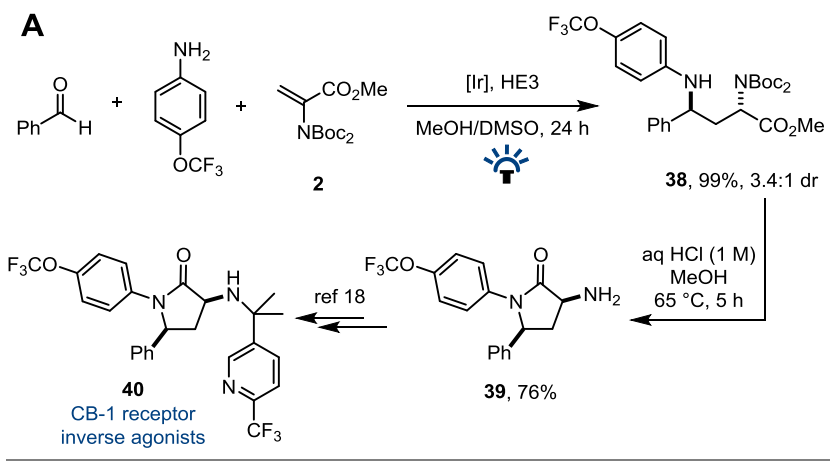

B
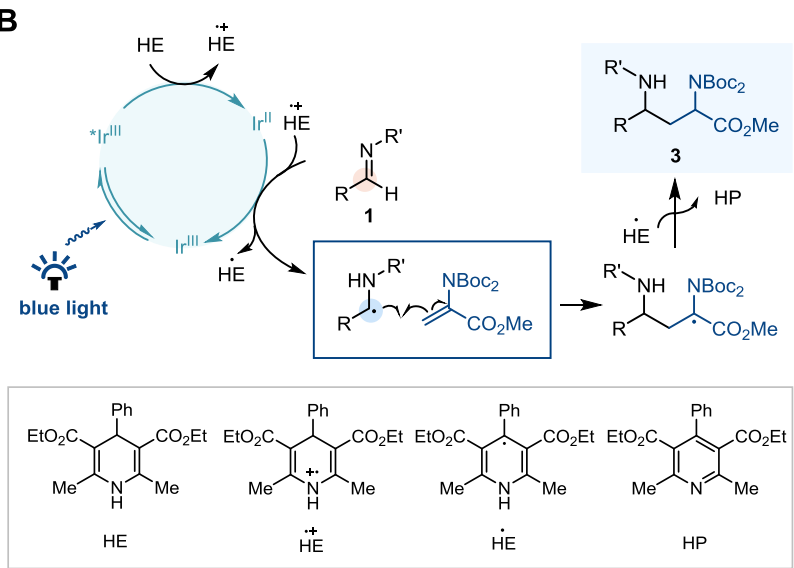

In conclusion, the first efficient photocatalytic one-pot umpolung coupling of imines and a DHA derivative $\mathbf{2}$ for the diastereoselective construction of 1,3-diamine products has been developed in high yield and moderate to good diastereoselectivity. A broad functional group tolerance has been demonstrated with respect to both the aldehyde and the amine moiety, showcasing its potential in medicinal chemistry applications. Remarkable reaction efficiency was demonstrated for heterocyclic compounds and imines derived from aliphatic aldehydes. Further extension of the photocatalytic platform to $\beta$-amino alcohol synthesis and derivatization to biologically relevant $\gamma$-lactams illustrate the applicability of this new umpolung coupling methodology. Efforts to develop this concept further and establish enantioselective variants are ongoing.

\section{ASSOCIATED CONTENT}

The Supporting Information is available free of charge on the ACS Publications website. Synthetic procedures and full characterization data of compounds (PDF) Full crystallographic data (CIF)

\section{AUTHOR INFORMATION}

\section{Corresponding Author}

* Darren J. Dixon: darren.dixon@chem.ox.ac.uk

\section{ACKNOWLEDGMENT}

DJD and TR wish to thank Astex Pharmaceuticals Ltd. for generous financial support and Dr Steven Howard (Astex Pharmaceuticals Ltd.) for fruitful discussion. JAL would like to thank the Leverhulme Trust (RPG-2017-069) for a research fellowship. We also thank Heyao Shi (University of Oxford) for X-ray structure determination and Dr Amber L. Thompson and Dr Kirsten E. Christensen (Oxford Chemical Crystallography) for X-ray mentoring and help.

\section{REFERENCES}

(1) For selected reviews see: (a) Narayanam, J. M. R.; Stephenson, C. R. J. Visible light photoredox catalysis: applications in organic synthesis. Chem. Soc. Rev. 2011, 40, 102-113; (b) Prier, C. K.; Rankic, D. A.; MacMillan, D. W. C. Visible Light Photoredox Catalysis with Transition Metal Complexes: Applications in Organic Synthesis. Chem. Rev. 2013, 113, 5322-5363; (c) Skubi, K. L.; Blum, T. R.; Yoon, T. P. Dual Catalysis Strategies in Photochemical Synthesis. Chem. Rev. 2016, 116, 10035-10074; (d) Twilton, J.; Lee, C.; Zhang, P.; Shaw, M. H.; Evans, R. W.; MacMillan, D. W. C. The merger of transition metal and photocatalysis. Nat. Rev. Chem. 2017, 1, 0052; (e) Lee, K. N.; Ngai, M.-Y. Recent developments in transition-metal photoredox-catalysed reactions of carbonyl derivatives. Chem. Commun. 2017, 53, 13093-13112.

(2) For key publications see: (a) Condie, A. G.; Gonzalez-Gomez, J. C.; Stephenson, C. R. J. Visible-Light Photoredox Catalysis: Aza-Henry Reactions via C-H Functionalization. J. Am. Chem. Soc. 2010, 132, 1464-1465; (b) Pham, P. V.; Nagib, D. A.; MacMillan, D. W. C. Photoredox Catalysis: A Mild, Operationally Simple Approach to the Synthesis of $\alpha$ Trifluoromethyl Carbonyl Compounds. Angew. Chem. Int. Ed. 2011, 50, 6119-6122; (c) Nagib, D. A.; MacMillan, D. W. C. Trifluoromethylation of arenes and heteroarenes by means of photoredox catalysis. Nature 2011, 480, 224-228; (d) Rono, L. J.; Yayla, H. G.; Wang, D. Y.; Armstrong, M. F.; Knowles, R. R. Enantionselective Photoredox Catalysis Enabled by ProtonCoupled Electron Transfer: Development of an Asymmetric Aza-Pinacol Cyclization. J. Am. Chem. Soc. 2013, 135, 17735-17738; (e) Zuo, Z.; Ahneman, D. T.; Chu, L.; Terrett, J. A.; Doyle, A. G.; MacMillan, D. W. C. Merging photoredox with nickel catalysis: Coupling of $\alpha$-carboxyl $\mathrm{sp}^{3}-$ carbons with aryl halides. Science 2014, 345, 437-440; (f) Noble, A.; MacMillan, D. W. C. Photoredox $\alpha$-Vinylation of $\alpha$-Amino Acids and $N$ Aryl Amines. J. Am. Chem. Soc. 2014, 136, 11602-11605; (g) Uraguchi, D.; Kinoshita, N.; Kizu, T.; Ooi, T. Synergistic Catalysis of Ionic Brønsted Acid and Photosensitizer for a Redox Neutral Asymmetric $\alpha$-Coupling of N-Arylaminomethanes with Aldimines. J. Am. Chem. Soc. 2015, 137, 13768-13771; (h) Choi, G. J.; Zhu, Q.; Miller, D. C.; Gu, C. J.; Knowles, R. $\mathrm{R}$. Catalytic alkylation of remote $\mathrm{C}-\mathrm{H}$ bonds enabled by proton-coupled electron transfer. Nature 2016, 539, 268-271; (i) Matsui, J. K.; Lang, S. B.; Heitz, D. R.; Molander, G. A. Photoredox-Mediated Routes to Radicals: The Value of Catalytic Radical Generation in Synthetic Methods Development. ACS Catal. 2017, 7, 2563-2575; (1) Zheng, W.; Morales-Rivera, C. A.; Lee, J. W.; Liu, P.; Ngai, M.-Y. Catalytic C-H Trifluoromethoxylation of Arenes and Heteroarenes. Angew. Chem. Int. Ed. 2018, 57, 9645-9649; (m) Wang, C.; Qin, J.; Shen, X.; Riedel, R.; Harms, K.; Meggers, E. Asymmetric Radical-Radical Cross-Coupling through Visible-Light-Activated Iridium Catalysis. Angew. Chem. Int. Ed. 2016, 55, 685-688; (n) Hari, D. P.; Schroll, P.; König, B. Metal-Free, Visible-Light-Mediated Direct C-H Arylation of Heteroarenes with Aryl Diazonium Salts. J. Am. Chem. Soc. 2012, 134, 2958-2961.

(3) (a) Qi, L.; Chen, Y. Polarity-Reversed Allylations of Aldehydes, Ketones, and Imines Enabled by Hantzsch Ester in Photoredox Catalysis. Angew. Chem. Int. Ed. 2016, 55, 13312-13315; (b) Fuentes de Arriba, A. L.; Urbitsch, F.; Dixon, D. J. Umpolung synthesis of branched $a-$ functionalized amines from imines via photocatalytic three-component reductive coupling reactions. Chem. Commun. 2016, 52, 14434-14437.

(4) (a) Lee, K. N.; Lei, Z.; Ngai, M.-Y. $\beta$-Selective Reductive Coupling of Alkenylpyridines with Aldehydes and Imines via Synergistic Lewis Acid/Photoredox Catalysis. J. Am. Chem. Soc. 2017, 139, 5003-5006; (b) 
Fava, E.; Millet, A.; Nakajima, M.; Loescher, S.; Rueping, M. Reductive Umpolung of Carbonyl Derivatives with Visible-Light Photoredox Catalysis: Direct Access to Vicinal Diamines and Amino Alcohols via $\alpha$-Amino Radicals and Ketyl Radicals. Angew. Chem. Int. Ed. 2016, 55, 6776-6779; (c) Nakajima, M.; Fava, E.; Loescher, S.; Jiang, Z.; Rueping, M. Photoredox-Catalyzed Reductive Coupling of Aldehydes, Ketones, and Imines with Visible Light. Angew. Chem. Int. Ed. 2015, 54, 8828-8832; (d) Hager, D.; MacMillan, D. W. C. Activation of C-H Bonds via the Merger of Photoredox and Organocatalysis: A Coupling of Benzylic Ethers with Schiff Bases. J. Am. Chem. Soc. 2014, 136, 16986-16989; (e) Uraguchi, D.; Kinoshita, N.; Kizu, T.; Ooi, T. Synergistic Catalysis of Ionic Brønsted Acid and Photosensitizer for a Redox Neutral Asymmetric $\alpha$-Coupling of $\mathrm{N}$ Arylaminomethanes with Aldimines. J. Am. Chem. Soc. 2015, 137, 1376813771; (f) Jeffrey, J. L.; Petronijevic, F. R.; MacMillan, D. W. C. Selective Radical-Radical Cross-Couplings: Design of a Formal $\beta$-Mannich Reaction. J. Am. Chem. Soc. 2015, 137, 8404-8407.

(5) Chen, M.; Zhao, X.; Yang, C.; Xia, W. Visible-Light-Triggered Directly Reductive Arylation of Carbonyl/Iminyl Derivatives through Photocatalytic PCET. Org. Lett. 2017, 19, 3807-3810.

(6) For further examples see: (a) Zhou, N.; Yuan, X.-A.; Zhao, Y.; Xie, J.; Zhu, C. Synergistic Photoredox Catalysis and Organocatalysis for Inverse Hydroboration of Imines. Angew. Chem. Int. Ed. 2018, 57, 39903994; (b) Rong, J.; Seeberger, P. H.; Gilmore, K. Chemoselective Photoredox Synthesis of Unprotected Primary Amines Using Ammonia. Org. Lett. 2018, 20, 4081-4085; (c) Guo, X.; Wenger, O. Reductive Amination by Photoredox Catalysis and Polarity-Matched Hydrogen Atom Transfer. Angew. Chem. Int. Ed. 2018, 57, 2469-2473; (d) van As, D. J.; Connell, T. U.; Brzozowski, M.; Scully, A. D.; Polyzos, A. Photocatalytic and Chemoselective Transfer Hydrogenation of Diarylimines in Batch and Continuous Flow. Org. Lett. 2018, 20, 905-908; (e) Wang, R.; Ma, M.; Gong, X.; Panetti, G. B.; Fan, X.; Walsh, P. J. Visible-Light-Mediated Umpolung Reactivity of Imines: Ketimine Reductions with Cy2NMe and Water. Org. Lett. 2018, 20, 24332436.

(7) Leitch, J. A.; Fuentes de Arriba, A. L.; Tan, J.; Hoff, O.; Martinez, C. M.; Dixon, D. J. Photocatalytic reverse polarity Povarov reaction. Chem. Sci. 2018, 9, 6653-6658.

(8) Ji, X.; Huang, H. Synthetic methods for 1,3-diamines. Org. Biomol. Chem. 2016, 14, 10557-10566.

(9) Li, K.; Webber, A. E.; Tseng, L.; Malcolmson, S. J. Diastereoselective and Enantiospecific Synthesis of 1,3-Diamines via 2-Azaallyl Anion Benzylic Ring-Opening of Aziridines. Org. Lett. 2017, 19, 4239-4242.

(10) (a) Aycock, R. A.; Vogt, D. B.; Jui, N. T. A practical and scalable system for heteroaryl amino acid synthesis. Chem. Sci. 2017, 8, 7998-8003. Photocatalytic radical addition has also been applied to functionalization to DHA-containing proteins: (b) Aycock, R. A.; Pratt, Cameron, J.; Jui, N. T. Aminoalkyl Radicals as Powerful Intermediates for the Synthesis of Unnatural Amino Acids and Peptides, ACS Cat. 2018, 8, 9115-9119.

(11) (a) Boyington, A. J.; Riu, M.-L. Y.; Jui, N. T. Anti-Markovnikov Hydroarylation of Unactivated Olefins via Pyridyl Radical Intermediates. J. Am. Chem. Soc. 2017, 139, 6582-6585; (b) Aycock, R. A.; Wang, H.; Jui, N. T. A mild catalytic system for radical conjugate addition of nitrogen heterocycles. Chem. Sci. 2017, 8, 3121-3125; (c) Yin, Y.; Dai, Y.; Jia, H.; Li, J.; Bu, L.; Qiao, B.; Zhao, X.; Jiang, Z. Conjugate AdditionEnantioselective Protonation of N-Aryl Glycines to $a$-Branched 2Vinylazaarenes via Cooperative Photoredox and Asymmetric Catalysis. J. Am. Chem. Soc. 2018, 140, 6083-6087; (d) Phelan, J. P.; Lang, S. B.; Compton, J. S.; Kelly, C. B.; Dykstra, R.; Gutierrez, O.; Molander, G. A. Redox-Neutral Photocatalytic Cyclopropanation via Radical/Polar Crossover. J. Am. Chem. Soc. 2018, 140, 8037-8047.

(12) Crystal data for anti-3 can be found at CCDC 1857913.

(13) See Supporting Information for further details.

(14) Mass balance in these reactions is 4-fluoroaniline and imine

(15) Lee, H.-S.; Kang, S. H. Synthesis of Physiologically Potent $\beta$ Amino Alcohols Synlett. 2004, 1673-1685.
(16) Lait, S. M.; Rankic, D. A.; Keay, B. A. 1,3-Aminoalcohols and Their Derivatives in Asymmetric Organic Synthesis. Chem. Rev. 2007, 107, 767796.

(17) Hu, J. PCT Int. Appl. 2011, US 20110028520A1.

(18) So, S. S.; Auvil, T. J.; Garza, V. J.; Mattson, A. E.; Keay, B. A. Boronate Urea Activation of Nitrocyclopropane Carboxylates. Org. Lett. 2012, $14,444-447$.

(19) Sharma, M. K.; Murumkar, P. R. M.; Barmade, A.; Giridhar, R.; Yadav, M. R. A comprehensive patents review on cannabinoid 1 receptor antagonists as antiobesity agents. Expert. Opin. Ther. Pat. 2015, 25, 10931116.

(20) Gentry, E. C.; Knowles, R. R. Synthetic Applications of ProtonCoupled Electron Transfer. Acc. Chem. Res. 2016, 49, 1546-1556.

(21) Roth, H. G.; Romero, N. A.; Nicewicz, D. A. Experimental and Calculated Electrochemical Potentials of Common Organic Molecules for Applications to Single-Electron Redox Chemistry. Synlett 2016, 27, 714723. 


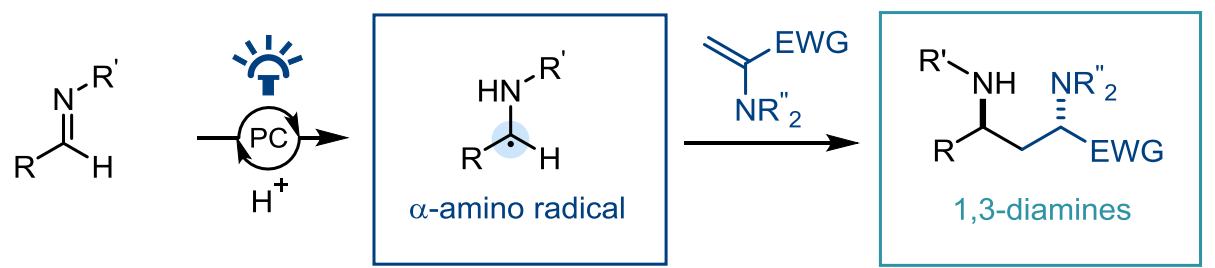

- one-pot photocatalytic reductive coupling - high functional group tolerance with up to $99 \%$ yield - efficient with aliphatic $R$ 